\title{
Attenuation of Kindled Seizures by Intranasal Delivery of Neuropeptide-Loaded Nanoparticles
}

\author{
Michael J. Kubek, ${ }^{* \dagger}$ Abraham J. Domb ${ }^{\S}$ and Michael C. Veronesi ${ }^{\ddagger}$ \\ Departments of *Anatomy and Cell Biology and ${ }^{\dagger}$ Psychiatry and ${ }^{\ddagger}$ Program in Medical Neuroscience, Indiana University School \\ of Medicine, Indianapolis, Indiana 46202; and ${ }^{\S}$ Department of Pharmaceutical Chemistry, Hadassa Medical Center, The Hebrew \\ University, Jerusalem, Israel 91120
}

\begin{abstract}
Summary: Thyrotropin-releasing hormone (TRH; Protirelin), an endogenous neuropeptide, is known to have anticonvulsant effects in animal seizure models and certain intractable epileptic patients. Its duration of action, however, is limited by rapid tissue metabolism and the blood-brain barrier. Direct nose-tobrain delivery of neuropeptides in sustained-release biodegradable nanoparticles (NPs) is a promising mode of therapy for enhancing CNS neuropeptide bioavailability. To provide proof of principle for this delivery approach, we used the kindling model of temporal lobe epilepsy to show that 1) TRH-loaded copolymer microdisks implanted in a seizure focus can attenuate kindling development in terms of behavioral stage, afterdischarge duration (ADD), and clonus duration; 2) intranasal administration of an unprotected TRH analog can acutely suppress fully kindled seizures in a concentration-dependent manner in terms of ADD and seizure stage; and 3) intranasal
\end{abstract}

administration of polylactide nanoparticles (PLA-NPs) containing TRH (TRH-NPs) can impede kindling development in terms of behavioral stage, ADD, and clonus duration. Additionally, we used intranasal delivery of fluorescent dye-loaded PLA-NPs in rats and application of dye-loaded or dye-attached NPs to cortical neurons in culture to demonstrate NP uptake and distribution over time in vivo and in vitro respectively. Also, a nanoparticle immunostaining method was developed as a procedure for directly visualizing the tissue level and distribution of neuropeptide-loaded nanoparticles. Collectively, the data provide proof of concept for intranasal delivery of TRH-NPs as a viable means to 1) suppress seizures and perhaps epileptogenesis and 2) become the lead compound for intranasal anticonvulsant nanoparticle therapeutics. Key Words: TRH, drug delivery, intranasal, kindling, thyrotropin-releasing hormone, epilepsy therapy.

\section{INTRODUCTION}

Thyrotropin-releasing hormone (L-pyroglutamyl-L-histidylL-prolineamide) (TRH; Protirelin) was the first endogenous neuropeptide to be fully characterized in animals and humans. In addition to its neuroendocrine role in regulating the hypothalamic-pituitary axis, TRH has a noteworthy presence in limbic system areas. ${ }^{1-3}$ TRH, its metabolic enzymes (PAP I, PAP II), TRH mRNA, posttranslational processing enzymes (PC1, PC2), and TRH receptors (TRH-R1, TRH-R2) are most abundant in olfactory-linked limbic structures, such as the amygdala, septum, hippocampus, and entorhinal cortex. ${ }^{1,4-7}$ Moreover, both TRH and TRH mRNAs are upregulated substantially over several days, whereas TRH receptors and

Address correspondence and reprint requests to: Michael J. Kubek, Department of Anatomy \& Cell Biology, Indiana University School of Medicine, 635 Barnhill Drive, Indianapolis, IN 46202-5120. E-mail: mjkubek@iupui.edu. receptor mRNAs are downregulated in specific seizureprone areas such as the amygdala and hippocampus after electroconvulsive and amygdala-kindled seizures. ${ }^{8-14}$

Recent reports have documented an anticonvulsant role of TRH, from animal studies ${ }^{15-20}$ to clinical trials in intractable epilepsies such as West syndrome and Lennox-Gastaut syndrome, with none of the reported morbidity or mortality seen with current therapy. ${ }^{21-24}$ The status of the blood-brain barrier (BBB) in these syndromes is not well established, and in fact may permit greater neuropeptide penetration to the CNS. Nonetheless, use of TRH or analogs for other intractable epilepsies such as seen in the temporal lobe has not yet appeared. $^{21}$

The antiepileptic effect of TRH observed clinically and in animals suggests a novel mechanism of action and represents a potential new class of anticonvulsants, neuropeptides. $^{25,26}$ Therapeutically, site-specific sustained bioavailability of neuropeptides in general is compromised because of an inability to cross the BBB and rapid 
rates of metabolism in several tissue compartments by endogenous specific and nonspecific endopeptidases. ${ }^{27,28}$ Recent studies have provided proof of concept in humans of relatively rapid neuropeptide transport from nose to cerebrospinal fluid. ${ }^{29-31}$ The intranasal route of delivery presents a possible alternative route of administration for TRH and other neuropeptides, accessing the brain through the nasal cavity by way of transport through the olfactory neuroepithelium. ${ }^{32}$

Substances the size of nanoparticles can enter the olfactory neurons by way of receptor-mediated uptake, ${ }^{33}$ bulk endocytosis, ${ }^{34}$ or pinocytosis ${ }^{34,35}$ across the dendrosomatic membrane. Once inside the olfactory neuron, the unmyelinated axon projecting through the cribriform plate and synapsing within the olfactory bulb allows for direct transport of substances from the nasal cavity to the brain. ${ }^{36}$ Direct and indirect projections from the olfactory bulb innervate seizurogenic regions in the temporal lobe, such as the amygdala, piriform and entorhinal cortices, and hippocampal formation. ${ }^{33,37}$ Supporting cells or Bowman's glands may allow an additional, non-neuronal epithelial pathway for entry of compounds into the brain by way of pinocytosis, diffusion or paracellular transport through cell junctions. ${ }^{37-39}$

As opposed to the neuronal pathway, drugs appear in the CSF and brain a few minutes after nasal application when transported through the non-neuronal pathway. ${ }^{29,39}$ The preferred route by which intranasally administered drugs and nanoparticles gain entry to the CNS from the olfactory epithelium is presently unknown. Intranasal delivery is not a new concept, but the synthesis of newer biodegradable polymers in nanoparticle formulations as neuropeptide carriers has generated renewed interest in this approach to CNS drug delivery.

The studies presented in this review aim to provide current proof of principle that in situ delivery of sustained-release biodegradable microdisks and intranasal delivery of neuropeptide-loaded biodegradable nanoparticles may provide a new approach in seizure therapy.

\section{KINDLING PARADIGM}

Our work has focused on the kindling paradigm as an animal model of temporal lobe epilepsy and epileptogenesis. Kindling is a chronic electrically or chemically induced animal model of epilepsy that mimics partial seizures that progress to become generalized; kindling has been studied more extensively than any other temporal lobe epilepsy or seizure model. ${ }^{40}$ Recurrent, subconvulsive, electrical stimulation of certain brain structures, such as the amygdala or hippocampus, can reliably lead to fully kindled seizures. ${ }^{41}$

Full kindling is permanent and includes behavioral, electrophysiological, neuroanatomical, and neurochemical characteristics associated with partial and generalized seizures. Limbic kindling begins with establishing the afterdischarge threshold (ADT), an initial focal seizure response at the stimulated site that is expressed on the EEG as an epileptiform discharge. With repeated daily subconvulsive electrical stimulations, the afterdischarges (ADs) become progressively more complex and prolonged until generalized tonic-clonic seizures (stage V) seizures occur. ${ }^{42}$ After four to five consecutive stage $\mathrm{V}$ seizures, the animal is said to be permanently kindled. ${ }^{41}$

A brief description of the kindling procedure and nasal port implantation used in our lab is provided, because all studies in this review used this basic or updated kindling protocol. The nasal port and stimulating electrode implantation procedure, as well as the kindling procedure, have been detailed previously. ${ }^{12,19}$ Male Sprague-Dawley rats (60-65 days of age) (Harlan Industries, Indianapolis, IN) were maintained under controlled environmental conditions conducted in compliance with the animal welfare act and in adherence to the principles set forth in the Guide for the Care and Use of Laboratory Animals, National Institutes of Health publication 86-23, 1985 edition.

On the day of surgery, rats (290-300 g) were anesthetized, the head was secured in stereotaxic apparatus (model 1504; David Kopf Instruments, Tujunga, CA), and anesthesia was maintained at $1.75 \%$ isoflurane. Bipolar stainless steel electrodes (Plastics One, Roanoke, VA) were implanted into the basolateral amygdala bilaterally using stereotaxic coordinates from the atlas of Paxinos and Watson ${ }^{43}$ (incisor bar: $-3.3 \mathrm{~mm}$; anteriorposterior: $-2.8 \mathrm{~mm}$ from bregma; left/right $\pm 5.0 \mathrm{~mm}$ from bregma; dorsal/ventral $-8.5 \mathrm{~mm}$ from skull). A ground screw (Plastics One, Roanoke, VA) was placed in the skull lateral $(\sim 2.0 \mathrm{~mm})$ and anterior $(\sim 2.0 \mathrm{~mm})$ to the bregma. Once the head cap was secure in place, a midline incision was made to expose the nasofrontal suture. Immediately posterior to the nasofrontal suture, a $0.50-\mathrm{mm}$ diameter hole was drilled bilaterally to access the olfactory epithelium within the posterior nasal cavity immediately anterior to the cribriform plate. Stainless steel nasal ports were inserted into the holes and anchored to the skull with cranioplastic cement (Plastics One, Roanoke, VA) (FIG. 1).

After surgery, in addition to monitoring of weight gain, olfactory function in animals was assessed by observing preference for fruit-flavored snacks over normal chow. At the end of the study, gross examination of the nasal cavity was conducted on some animals to evaluate the placement of the nasal ports; no evidence of olfactory epithelium pathology was observed. An ADT was determined in each animal by administering stimulations of increasing current (from 60 to $120 \mu \mathrm{A}$, in increments of $20 \mu \mathrm{A}$ ) with 2-min intervals between stimulations until an afterdischarge (AD) was recorded on the electroencephalograph (EEG). All animals with 60-120 $\mu$ A ADTs 

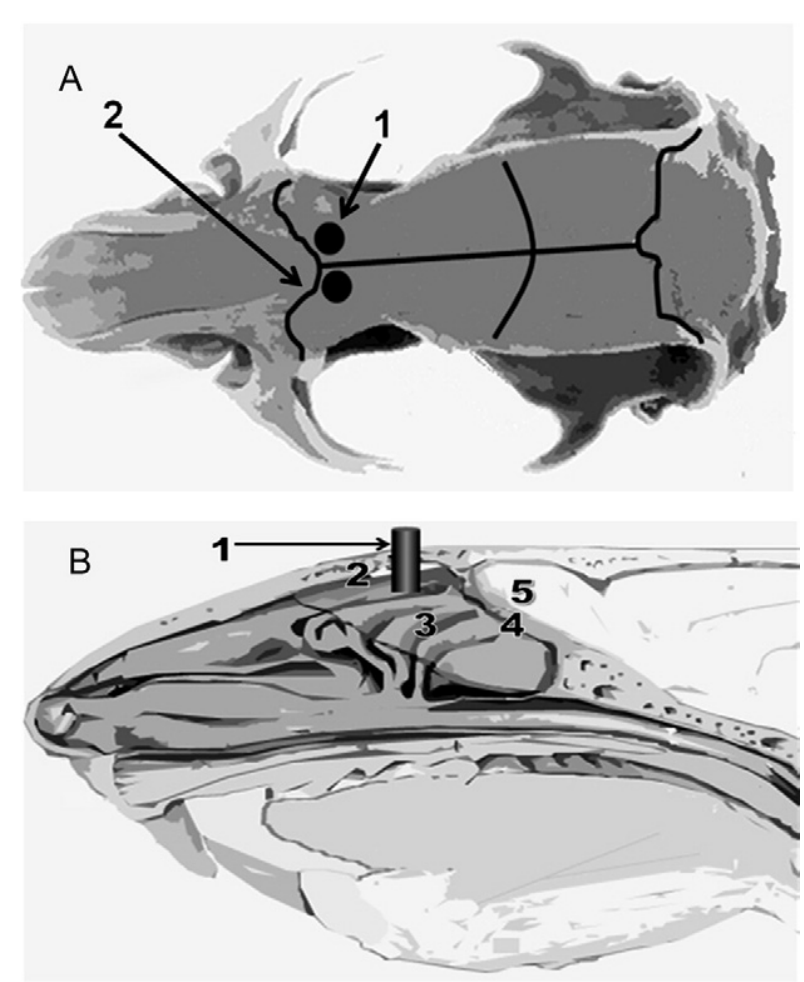

FIG. 1. Delivery ports implanted into the nasal cavity of the rat. A: Delivery ports (1) were implanted bilaterally, posterior to the nasofrontal suture (2), allowing entry onto the nasal cavity just anterior to the cribriform plate as shown from the dorsal view. B: The midsagittal view shows that the left nasal port (1) gains direct access to the nasal olfactory epithelium (3) from the outside when placed from posterior to the nasofrontal suture (2). The olfactory epithelium allows access to the olfactory bulb (5), after passage through the cribriform plate (4). Reprinted from Veronesi et al. ${ }^{19}$ (Epilepsia 2007;48:2280-2286), with permission of Blackwell Publishing.

were administered a daily stimulation consisting of a 1 -s train of $60-\mathrm{Hz}$ biphasic square-wave stimulations with peak-to-peak amplitude of 135-200 $\mu \mathrm{A}$ (mean ADT + $50 \mu \mathrm{A}$ ) generated by an S88 stimulator and constantcurrent converters (Grass Instruments, Quincy, MA). The EEGs (Model 79 EEG polygraph; Grass Instruments, Warwick, MA) were converted from an analog to digital signal using an $\mathrm{A} / \mathrm{D}$ converter, and stored in a desktop computer for analysis using the digital Polyview EEG Acquisition System (Grass Instruments, West Warwick, RI). Behavioral parameters of each seizure were captured simultaneously with EEG acquisition using a digital camera (V1.50.05; Creative Labs, Milpitas, CA) and stored for subsequent analysis. The classification of Racine $^{42}$ was used to score the behavioral component of kindling (stages I - V). The afterdischarge duration (ADD)/seizure duration, clonic activity, and behavioral seizure stage were acquired after each stimulation. Rats were stimulated once daily until four consecutive stage $\mathrm{V}$ seizures occurred, which marked the point at which the animals became fully kindled (permanent acquired temporal lobe epilepsy). ${ }^{41}$

\section{EFFECT OF SUSTAINED RELEASE MICRODISKS ON KINDLING DEVELOPMENT}

Wan et al. ${ }^{17}$ demonstrated that bilateral intrahippocampal injection of unprotected TRH can acutely reduce afterdischarge and seizure duration in previously kindled rats. Concurrently, we incorporated TRH into a surface-eroding biodegradable polyanhydride copolymer as a sustained-release microdisk carrier for stereotaxic implantation. These studies explored the notion that direct delivery of TRH to a seizure focus can impede seizure activity.

A single TRH microdisk (3.6 $\mu \mathrm{g}$ TRH) implanted stereotaxically into the seizure focus (amygdala) significantly suppressed kindling expression when evaluated by the number of stimulations required to reach each seizure stage and to become fully kindled $(8.63 \pm 0.92$ vs $16.17 \pm$ 1.37 , mean \pm S.E.M.). The TRH microdisks delayed AD transfer to the contralateral amygdala, and significantly shortened the AD duration in both the ipsilateral (stimulated) and contralateral amygdala during kindling. An example is given in FIG. 2. Two indices of seizure severity, afterdischarge duration (stimulated $87.40 \pm 5.47$ vs $51.80 \pm 15.65$, unstimulated amygdala: $89.60 \pm 5.55$ vs $48.67 \pm 15.8)$ and clonus duration $(71.2 \pm 5.94$ vs $29.40 \pm 8.87$ ) were also significantly reduced by a single microdisk implant. Remarkably, 50 days after initiation of the study, a significant reduction in clonus duration $(53.90 \pm 3.27$ vs $40.09 \pm 4.14)$ still remained in the TRH implanted groups. Moreover, implanted microdisks (with or without TRH) had no effect on afterdischarge threshold prior to kindling and no apparent change in animal behavior was evident throughout the study.

This suggests that polymeric TRH may be implanted into a known or potential seizure focus without apparently affecting ongoing neuronal activity. ${ }^{16}$ In addition, the safety of implanting biodegradable polymers into the brain has been demonstrated clinically. ${ }^{44}$ The amygdala is a key site of kindled seizures and has widespread connections with cortical and subcortical areas. It seems reasonable, therefore, to consider that site-specific sustained delivery of sufficient TRH is effective in substantially decreasing the level of excitability of amygdala efferents and that it retards the rate of seizure spread (or generalization) throughout the brain for a prolonged period.

Physiologically, densities for TRH receptors (TRH-R1, TRH-R2) are highest in temporal lobe areas most notably in the amygdala, piriform cortex, entorhinal cortex and hippocampal dentate gyrus ${ }^{5,45,46}$ which correlate well with known sites of temporal lobe seizure foci. Furthermore, it appears that the in situ delivery route was more effective than intravenous TRH delivery. ${ }^{18,47}$ Moreover, the data indicate that if sufficient TRH reaches the seizure focus over time the effect can be prolonged. These findings support the use of biodegradable sustained-release carriers clinically for potential neuropeptide delivery to site-specific CNS loci. ${ }^{16,17}$ 
A1

Stage 3

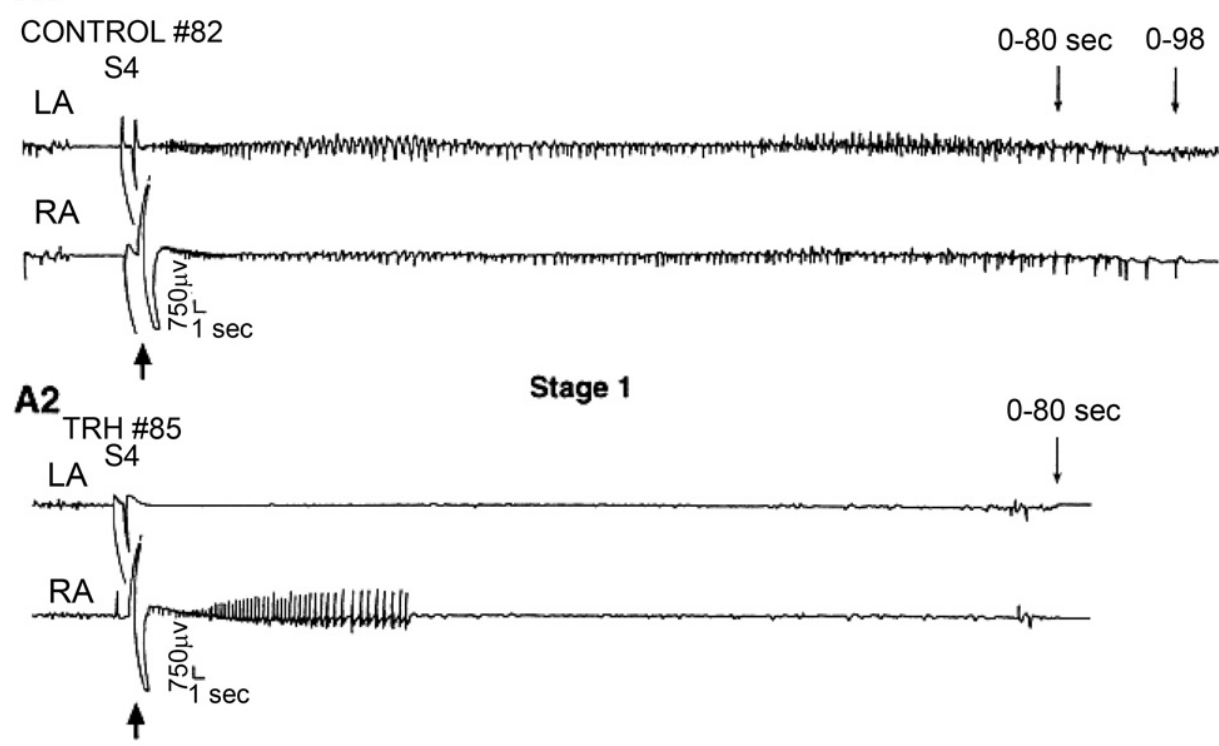

B1

Stage 5

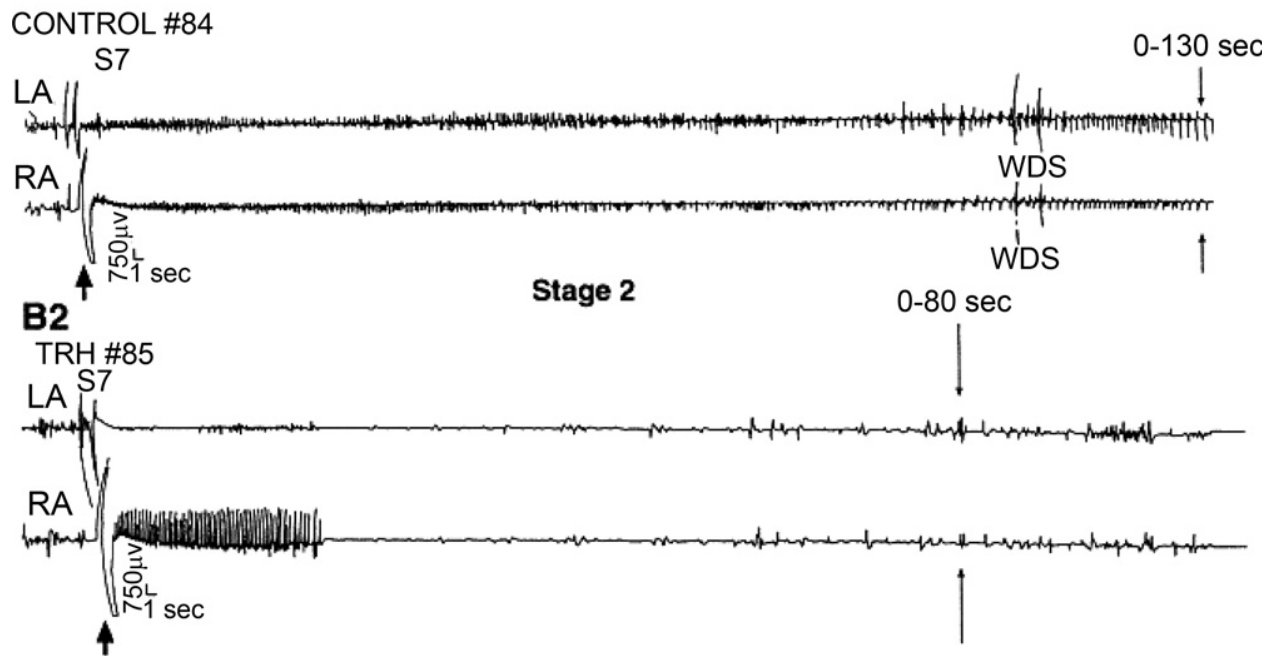

FIG. 2. Representative bilateral EEG recordings from the amygdala after the fourth (S4) and seventh (S7) kindling stimulation in thyrotropinreleasing hormone (TRH) microdisk implanted rats. In panels $A$ and $B$, the upper tracings ( $\mathrm{A} 1$ and $\mathrm{B} 1$ ) represent control rats (Control \#82 and \#84, respectively); the lower tracings (A2 and B2) represent TRH-microdisk implanted rat TRH \#85. A 200- $\mu$ A stimulus was given to the right amygdala (RA) of each animal, whereas the contralateral left amygdala (LA) was unstimulated. S4 (panel A) resulted in a prolonged afterdischarge duration (98 s) from both the RA and LA of the control animal (tracing A1). In marked contrast, tracing A2 depicts a short series of afterdischarges (24 s) from the stimulated RA and absence of stimulus transfer to the contralateral LA of the TRH-microdisk animal. Behaviorally, S4 resulted in a stage 3 response in the control rat (A1), whereas only a stage 1 response was observed in the TRH-microdisk animal (A2). S7 (panel B), resulted in prolonged afterdischarge duration (>130 s) from both the RA and LA of the control animal (tracing B1). In contrast, tracing B2 depicts a much shorter series of afterdischarges (28 s) from the stimulated RA and absence of transfer to the contralateral LA of the TRH-microdisk animal. Behaviorally, S7 resulted in a stage 5 generalized seizure in the control rat (B1), but only a stage 2 response was observed in the TRH-microdisk animal (B2). Legend: Thick arrows, kindling stimulation; thin arrows, afterdischarge duration; WDS, wet dog shakes. Reprinted from Kubek et al. ${ }^{16}$ (Brain Res 1998;809:189-197), with permission of Elsevier Publishing.

This therapeutic approach can be effective in delivery of drugs directly to single or multiple seizure foci bilaterally, and is potentially useful also in prophylactic treatment of mirror foci. The results also imply that a sustained therapeutic level of an anticonvulsant neuropeptide that can be delivered to seizurogenic foci noninvasively, perhaps intranasally, could result in efficacious therapy as well.

\section{EFFECT OF INTRANASAL DELIVERY OF UNPROTECTED TRH ON FULLY KINDLED SEIZURES}

Therapeutically, clinical anticonvulsants such as midazolam have been successfully delivered intranasally in the management of acute seizures. ${ }^{48,49}$ Intranasal deliv- 
ery represents a feasible method also for neuropeptides that are not otherwise bioavailable to bypass the BBB and exert therapeutic effects in the CNS. ${ }^{39,50}$ For instance, nerve growth factor (NGF), insulin-like growth factor (IGF-I), estrogen, and interferon- $\beta$ have all been shown to reach the CNS after intranasal administration. ${ }^{38,51-53}$ Intranasal administration of NAP, an 8-amino acid peptide, has been shown to be neuroprotective and to exert cognitive enhancing properties in mice, ${ }^{54,55}$ and melanocortin and insulin are found in the cerebrospinal fluid (CSF) after intranasal administration in humans. ${ }^{29}$ Chepurnov et al ${ }^{56}$ recently reported that intranasal application of TRH significantly attenuated pentylenetetrazole-induced generalized seizures. This prompted us to examine this approach in the kindling paradigm using a metabolically stable TRH analog. ${ }^{19}$

In our hands, intranasal delivery of 3-methyl-histidine TRH (3Me-H TRH) $\left(10^{-9}, 10^{-8}, 10^{-7} \mathrm{~mol} / \mathrm{L}\right)$ administered at 60 and 30 min prior, but not 120 and 90 min prior, to a seizure stimulus significantly $(p<0.05)$ reduced total seizure duration in a concentration-dependent manner (22\%, 31.5\%, $44 \%$ respectively). Regression analysis revealed a linear relationship between increasing $3 \mathrm{Me}-\mathrm{H}$ TRH and attenuation of the total seizure duration $(y=$ $\left.-18.48 x+143.6, R^{2}=0.968\right)$. The time spent in stages I-IV was significantly $(p<0.05)$ reduced relative to saline control at the $10^{-8} \mathrm{~mol} / \mathrm{L}(27 \%)$ and $10^{-7} \mathrm{~mol} / \mathrm{L}(41.5 \%)$ concentrations (FIG. 3). Similarly, a reduction of time spent in stage $\mathrm{V}$ was also significant at the $10^{-8} \mathrm{~mol} / \mathrm{L}(58.5 \%)$ and $10^{-7} \mathrm{~mol} / \mathrm{L}(62.5 \%) 3 \mathrm{Me}-\mathrm{H}$ TRH concentrations (FIG. 3). Although not statistically significant, intranasal delivery of $10^{-9} \mathrm{~mol} / \mathrm{L} 3 \mathrm{Me}-\mathrm{H}$ TRH showed a tendency toward reduction of both the partial and generalized seizure response (FIG. 3). Forelimb and hindlimb clonic activity during a seizure may be considered a measure of seizure severity. ${ }^{16}$ Although clonus duration in treated animals was significantly reduced only at the $10^{-7} \mathrm{~mol} / \mathrm{L}$ concentration (31\%) (FIG. 3), regression analysis revealed a linear relationship between increasing $3 \mathrm{Me}-\mathrm{H}$ TRH and a reduction in seizure severity $\left(y=-6.13 x+68.15, R^{2}=0.973\right)$.

These data demonstrate that an analog of TRH, delivered intranasally at nanomolar concentrations, can significantly reduce several seizure parameters in fully kindled animals for up to $1 \mathrm{~h}$ after administration..$^{19}$ Our results support and extend the work by Chepurnov et al., ${ }^{56}$ who reported that intranasal application of TRH significantly attenuated pentylenetetrazole-induced generalized seizures. The finding that $3 \mathrm{Me}-\mathrm{H}$ TRH signifi-

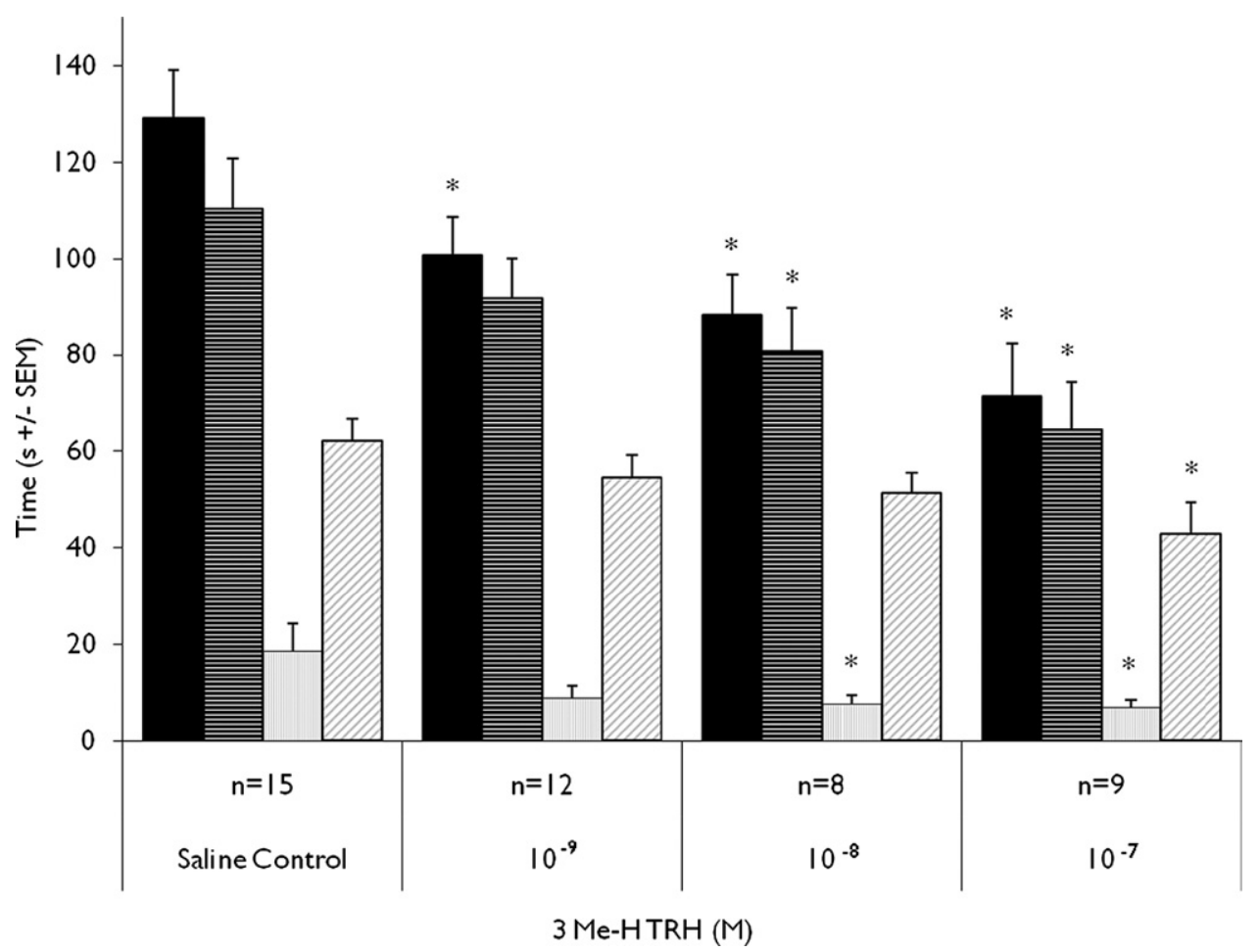

FIG. 3. Effect of intranasal 3-methyl-histidine TRH (3Me-H TRH) on seizure characteristics in fully kindled animals. $3 \mathrm{Me}-\mathrm{H}$ TRH $\left(10^{-9}\right.$, $10^{-8}$, and $\left.10^{-7} \mathrm{~mol} / \mathrm{L}\right)$ administered intranasally at 60 and 30 min before the seizure stimulus significantly $\left.{ }^{*} p<0.05\right)$ reduced total seizure duration $\left(22 \%, 31.5 \%\right.$, and $44 \%$ respectively) (solid black bars). The time spent in stages I-IV was significantly $\left({ }^{*} p<0.05\right)$ reduced compared with saline control after intranasal delivery of $10^{-8} \mathrm{~mol} / \mathrm{L}(27 \%)$ and $10^{-7} \mathrm{~mol} / \mathrm{L}(41.5 \%) 3 \mathrm{Me}-\mathrm{H} \mathrm{TRH}$, and delivery of $10^{-9} \mathrm{~mol} / \mathrm{L} 3 \mathrm{Me}-\mathrm{H}$ TRH showed a tendency toward reduction in stage I-IV seizure duration (black horizontal hatching). The time spent in stage $V$ was significantly $\left({ }^{*} p<0.05\right)$ reduced compared with saline control after intranasal delivery of $10^{-8} \mathrm{~mol} / \mathrm{L}(58.5 \%)$ and $10^{-7}$ $\mathrm{mol} / \mathrm{L}(62.5 \%) 3 \mathrm{Me}-\mathrm{H} \mathrm{TRH}$, and a tendency toward reduction in generalized seizure was seen at $10^{-9} \mathrm{~mol} / \mathrm{L}$ (gray bars). Clonus duration in treated animals was significantly $\left({ }^{*} p<0.05\right)$ reduced at the $10^{-7} \mathrm{~mol} / \mathrm{L}$ concentration $(31 \%)$ (gray diagonal hatching). Reprinted from Veronesi et al. ${ }^{19}$ (Epilepsia 2007;48:2280-2286), with permission of Blackwell Publishing. 
cantly reduced total seizure duration in a concentrationdependent manner has important implications, because it has been suggested that drugs that affect the ADD also tend to more efficaciously suppress behavioral symptoms. ${ }^{57}$ This result is similar to the effects of TRH after intracerebral administration, in which seizure duration was significantly attenuated in fully kindled animals, ${ }^{17}$ as well as during kindling development. ${ }^{16}$

The TRH analog had significant concentration-dependent effects on behavioral stages I through IV and on stage $\mathrm{V}$ seizures. We previously demonstrated a prolonged effect of sustained-release TRH on clonus duration. ${ }^{16}$ After intranasal delivery, 3Me-H TRH significantly reduced clonus duration only at the highest concentration, although a tendency toward reduction was evident at all concentrations. This suggests that prolonged bioavailability is essential for continued efficacy. The findings that all but two of the 3Me-H TRH-treated animals experienced less than a stage $\mathrm{V}$ seizure is in accord with another report that TRH or its analogs, when delivered into the dorsal hippocampus in fully kindled animals, had minimal effect on seizure stage but significantly reduced seizure duration. ${ }^{17}$

Collectively, several studies have now shown proof of principle for the intranasal approach to neuropeptide delivery to the CNS. Unfortunately, our findings and those of Chepurnov et al. ${ }^{56}$ revealed a significant limitation in this delivery method, in that a substantial number of smaller, unprotected, rapidly metabolized neuropeptides delivered intranasally would fail to provide a sustainable therapeutic effect—most likely because of rapid metabolism.

\section{EFFECT OF INTRANASAL DELIVERY OF TRH NANOPARTICLES ON KINDLING DEVELOPMENT}

Although the results just discussed provide proof of principle for the intranasal route of TRH delivery to the CNS, it is apparent that sustained bioavailability is essential for a feasible therapeutic effect. Methods developed to deliver neuropeptides via liposomes and capsular carriers have not been effective. ${ }^{16,32,58-60}$

Early sustained-release formulations of TRH-containing Copoly ((+)-lactic/glycolic acid) (PLGA) microspheres injected subcutaneously caused a dose-dependent shortening of pentobarbitone-induced sleeping time ${ }^{61}$ and improved experimentally induced parkinsonism ${ }^{62}$ in rats, but at levels known to stimulate an unwanted endocrine response. Therefore, sustained-release preparations loaded with neuropeptides in combination with the advantages obtained from intranasal delivery may provide the key elements for attaining more prolonged, site-specific effects while reducing unwanted side effects. ${ }^{32,63}$

Most recently reports have appeared showing intranasal uptake and delivery of nanoparticles to the brain but without demonstrating a subsequent physiological ef- fect. ${ }^{64}$ Our D,L-polylactide nanoparticles are submicronsized $(\sim 100 \mathrm{~nm})$ polymeric colloidal particles, with a therapeutic agent of interest (i.e., TRH) entrapped within their polymeric matrix. ${ }^{58-60}$ The use of TRH-NPs is hypothesized to increase target tissue bioavailability after intranasal delivery.

We proposed to demonstrate that intranasal delivery of TRH-loaded nanoparticles can suppress kindling development, as was demonstrated with our previous microdisk implant studies in situ. ${ }^{16}$ Thus, we pretreated two groups of rats with either TRH-NPs or unloaded NPs (Blank-NPs) 7 days before kindling. On day 8, kindling stimulations were initiated, along with intranasal NP treatment, and continued once a day until the subjects became fully kindled (permanently epileptic) or up to 20 stimulations.

The afterdischarge duration (ADD) of the TRH-NP treated group was significantly attenuated from the 10th to 13th stimulations (FIG. 4). Moreover, the number of stimulations required to reach the first stage $\mathrm{V}$ seizure and to become fully kindled (4 consecutive stage $\mathrm{V}$ seizures) was significantly prolonged in the TRH-NP group (FIG. 5). This trend was evident at stage IV $(p<$ 0.08 ) and became significant by stage $\mathrm{V}$, with the transition to kindling permanence being most affected in the TRH-NP group (FIG. 5). TRH-NP therapy significantly $(p<0.05)$ delayed the onset to clonus $(1.61$

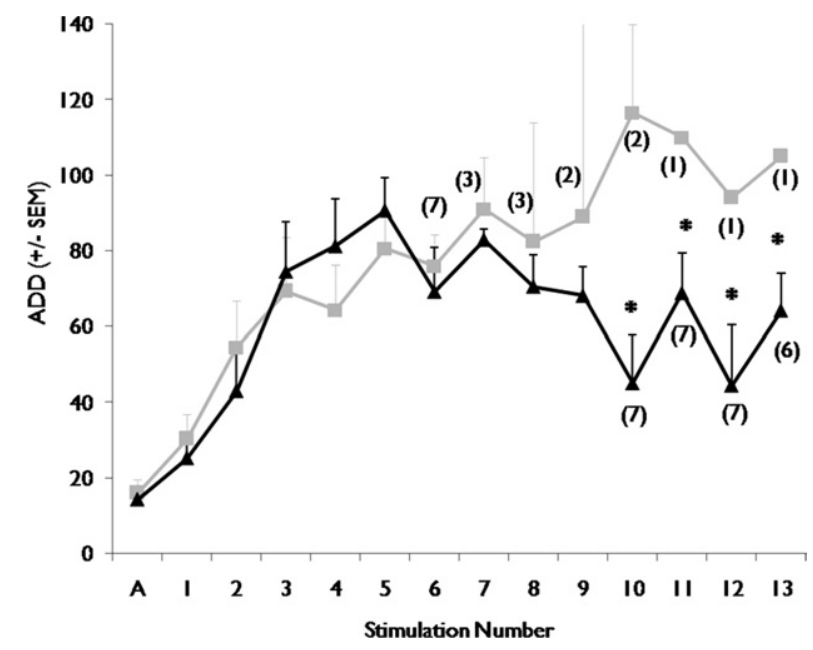

FIG. 4. Effect of intranasal TRH nanoparticles (TRH-NPs) on afterdischarge duration (ADD) in the amygdala during kindling. The ADD for the TRH-NP group (triangles) was significantly lower than the Blank-NP group (squares) as kindling progressed. Initially, both groups consisted of 8 rats each and subjects were removed from further stimulation once fully kindled (at four consecutive stage $V$ seizures), thus accounting for the decreasing number of subjects (indicated in parenthesis) beyond the 6th stimulation. Statistical analysis was performed on data from stimulations 1-13 using repeated measures ANOVA followed by Hochberg's step-up Bonferroni method. Error bars indicate means \pm S.E.M.; ${ }^{\star} p<0.05$. 


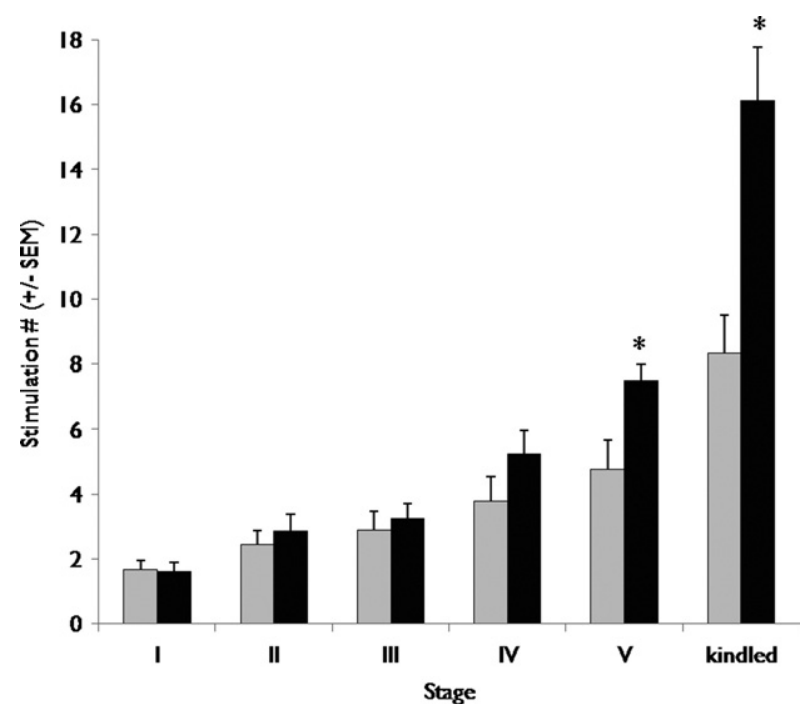

FIG. 5. Effect of intranasal TRH-NPs on kindling stage. The number of stimulations required to become fully kindled (permanently epileptic) was significantly greater for the TRH-NP group (gray bars) than for the Blank-NP group (black bars). The number of stimulations needed to reach stage $\mathrm{V}$ kindling was significantly greater for the TRH-NP group (gray bars) than the Blank-NP group (black bars). A trend toward suppression of kindling development was evident as early as stage IV $(p<0.08)$ with this intranasal dose of TRH-NPs. Statistical analysis was performed on the data using the Mann-Whitney test. Error bars indicate means \pm S.E.M. Kindled: the number of stimulations to achieve four consecutive stage $\mathrm{V}$ seizures; $\left.{ }^{*} p<0.05\right)$.

fold) and suppressed overall clonus duration (0.75 fold) during stage $\mathrm{V}$ seizures, compared with Blank NPs (data not shown). The TRH-NP treated animals showed no observable behavioral changes or significant weight change over the course of the study, indirectly indicating no apparent alteration in the pituitary-thyroid hormone axis. Future studies are planned to include direct measurement of endocrine-related hormones in plasma such as TSH, prolactin, and thyroxin after TRH-NP therapy.

These data mimic our earlier in situ TRH microdisk data, wherein several kindling characteristics were significantly attenuated after a 7-day priming period, including ADD, delay to clonus, and clonus duration ${ }^{16}$ — although the NP effects were not as robust. The design of this initial NP study did not include determination of TRH levels in the brain after intranasal delivery, because these studies are technically more difficult; they remain a subject for future research. One possible reason for the less robust NP response could be a lower concentration of TRH at the seizure focus. Nonetheless, we believe that these are the first data to appear that provide direct proof of concept for efficacy in the use of intranasal biodegradable nanoparticle seizure therapy. ${ }^{65,66}$ Taken together, our results strongly suggest that intranasal administration of sustained-release anticonvulsant neuropeptide nanoparticles may be a viable new means for suppressing temporal lobe seizures and other intractable seizures, such as West syndrome and Lennox-Gastaut syndrome.

\section{NANOPARTICLE CHARACTERISTICS}

Poly (L-lactic acid-D-lactic acid) nanoparticles (D,LPLA NPs) with or without TRH were prepared by the solvent evaporation method using a double emulsion process. Briefly D,L-PLA was prepared by ring-opening polymerization of L-lactide and D-lactide using stannous 1-ethylhexanoate $(\mathrm{Sn}(\mathrm{Oct}) 2)$ as a catalyst and benzyl alcohol as a co-catalyst. The synthesis and polymer analysis were as described previously. ${ }^{67}$ We used a particle analyzer and transmission electron microscopy (TEM) to characterize the size of the TRH nanoparticles, whereas the Nile red NPs were characterized by the particle analyzer alone. The particle sizes were determined at $25^{\circ} \mathrm{C}$ for $200 \mathrm{~s}$, using a Coulter N4 MD submicron particle size analyzer (Beckman Coulter, Fullerton, CA). Nile red loaded PLA nanoparticles used in the following studies were in the range of 88,100 , and $560 \mathrm{~nm}$ in diameter. For TEM NanoVan stain ( $\mathrm{pH}$ 8.0) (Nanoprobes, Stony Brook, NY) and nanoparticle-containing grids were examined at 50K (FIG. 6). The TRH nanoparticle samples measured with the particle analyzer and with TEM revealed a mean diameter of $108 \pm 12 \mathrm{~nm}$ for the TRHNPs and $102 \pm 12 \mathrm{~nm}$ for the Blank-NPs, demonstrating a uniformity of nanoparticle size and shape. ${ }^{68}$

The availability of NPs loaded with a fluorescent dye or with the dye attached to the nanoparticle has been a significant tool in determining uptake and distribution in nose-to-brain studies. Our goal was to determine the location of lipophilic Nile red released from 560-nm and 100-nm PLA NPs within the brain parenchyma after intranasal delivery, and the time course for its presence, using fluorescence microscopic visualization.

Intranasal delivery of a single application of 88- to 102-nm and 560-nm NPs loaded with Nile red were given to a series of rats. Uptake and transport into the brain occurred with the $88-\mathrm{nm}$ and $102-\mathrm{nm}$ particles but not the 560-nm particles (control: $560-\mathrm{nm}$ particles at $24 \mathrm{~h}$ after delivery) (FIG. 7). Using NIH Image-J software (NIH, Bethesda, MD; http://rsb.info.nih.gov/ij/) it was determined that the smaller particles were observed to transport and deliver the Nile red to several seizuresensitive areas of the rat brain at different rates (FIG. 7). These included the olfactory bulb and tract, septal nuclei, insular cortex, hippocampus, and thalamus. It was also found that the peak fluorescence occurred between 24 and $48 \mathrm{~h}$ after delivery, whereas fluorescence was still detectable up to $192 \mathrm{~h}$ (FIG. 7). These results indicate that the lipophilic dye is not simply released from the particles in the nasal cavity and absorbed by the olfactory epithelium but that the smaller particles are most likely taken up and transported to various sites and deliver the 

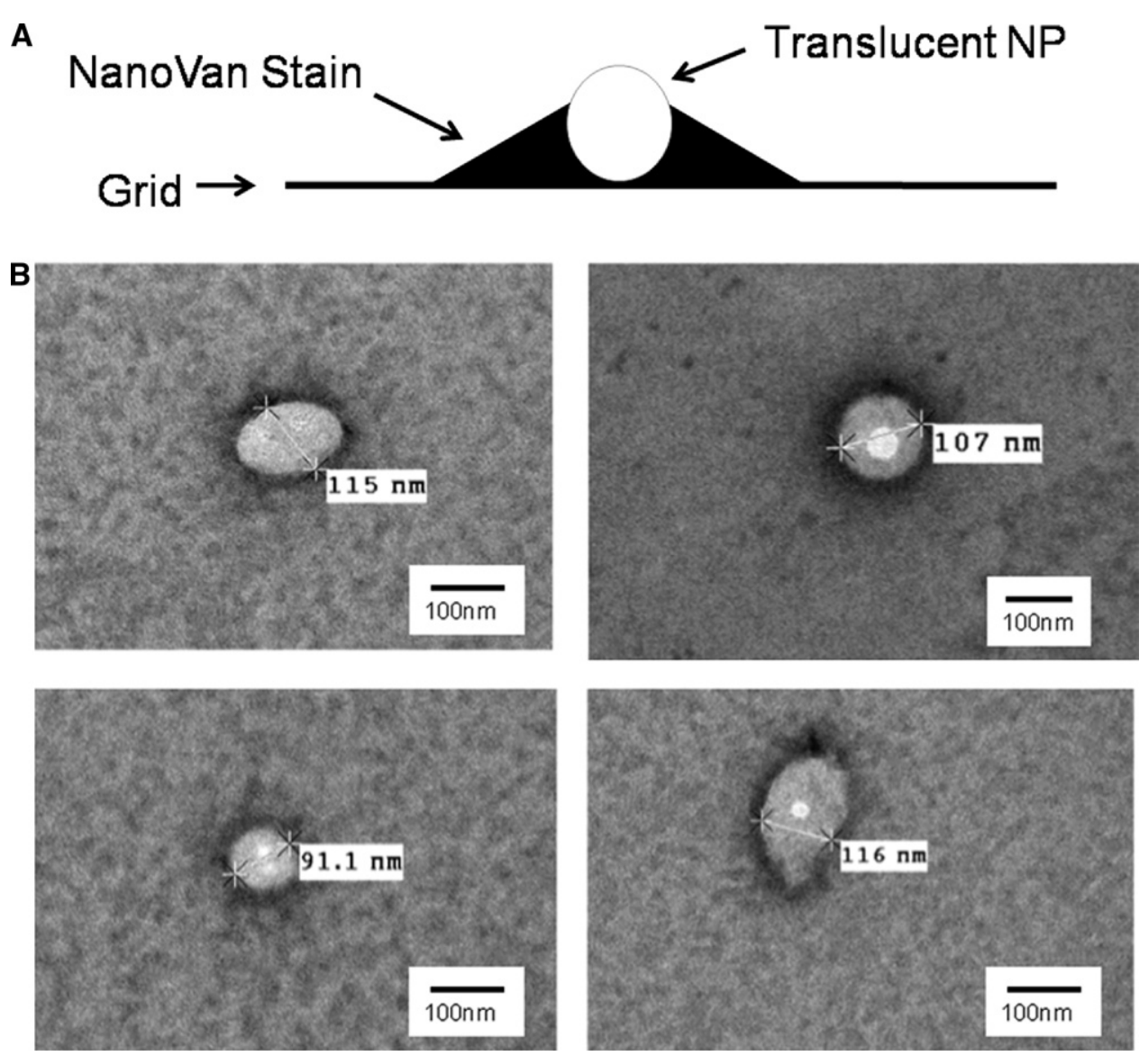

FIG. 6. Size determination of TRH nanoparticles using transmission electron microscopy. A: Schematic of a translucent nanoparticle made visible by the NanoVan stain applied to a 1-mm-diameter copper grid with a carbon film. B: Sample images of nanoparticles captured at 50,000× magnification using a Tecnai G2 12 Bio Twin transmission electron microscope (FEI, Hillsboro, OR) and AMT camera system (Advanced Microscopy Techniques, Danvers, MA).

dye whereas the larger particles were not. The data also suggest that the peak delivery with these nanocapsules in specific loci is heterogeneous. ${ }^{68}$

We have also conducted uptake studies in cultured hippocampal neurons. Fluorescence microscopy of dyeloaded and dye-attached NPs provided additional data on the uptake and transport of NPs in neuronal processes (FIG. 8). These data show that neurons are capable of endocytosing and transporting nanoparticles, and that this process could possibly occur in the olfactory neuroepithelium during intranasal delivery. ${ }^{68}$ We produced a highly specific polyclonal antibody to TRH that has been used for both immunocytochemistry and radioimmunoassay. ${ }^{69}$ Using this antibody, we have been able to visualize TRH-NPs in the brain, whereas Blank-NPs are undetectable (FIG. 9). This new technique provides the technology to specifically determine the uptake, timecourse, distribution, and concentration of TRH-NPs, as well as other neuropeptide nanoparticles, throughout the CNS and in other tissue compartments as well. This provides a very powerful semiquantitative tool to help determine the dose-response relationships necessary for achieving pharmacological effects in the future. ${ }^{68}$
In summary, we have shown that fluorescent dyeloaded nanoparticles, with nominal diameters in the range of 80 to $100 \mathrm{~nm}$, when applied in proximity to the olfactory neuroepithelium or neurons in culture, can be transported from nose to brain and in neuronal processes, respectively. Drug transport and metabolism in the nasal olfactory epithelia are incompletely understood, and anatomical and functional differences exist in the nasal mucosa of rats and humans. ${ }^{70}$ Nonetheless, nanoparticles are generally taken up efficiently by cells, penetrate deep into tissues, cross barriers present in epithelial linings, and appear to have minimal ciliotoxicity. ${ }^{64,71} \mathrm{New}$ insights into the various routes and mechanisms whereby drug-loaded nanoparticles are transported to the CNS are beginning to emerge. ${ }^{32,63,64,72}$

Clearly, much more work is needed to determine the mechanisms and kinetics of nasal port nanoparticle delivery. However, because the TRH loaded PLA NPs used in our studies were similar in size and composition to the Nile red NPs, it seems reasonable to consider that the TRH-NPs could have been transported from the targeted olfactory epithelium to the CNS in a similar manner to reach and sustain a bioactivity level sufficient to affect 

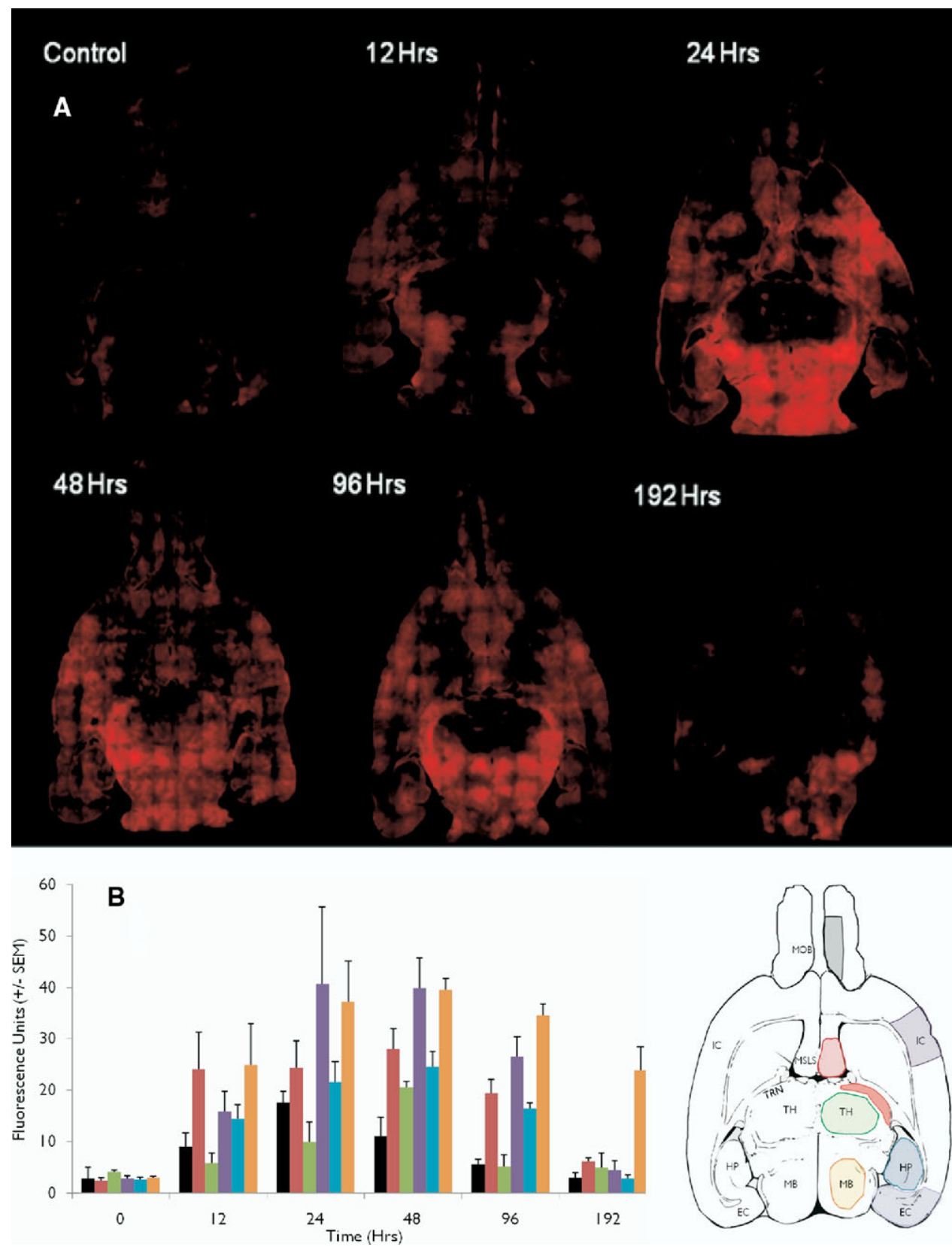

FIG. 7. Time course of Nile red fluorescence in the rat brain after intranasal nanoparticle delivery. A: Control fluorescence from $560-n m$ $\mathrm{NPs}, 24 \mathrm{~h}$ after intranasal delivery. For the intranasal uptake analysis, 130 digital images were captured for each sample at $4 \times$ magnification and montaged to reconstruct an entire horizontal brain section (Bioquant Imaging, Nashville, TN). The NIH Imagepixel-based analysis software program ( $\mathrm{NIH}$, Bethesda, MD) was used to analyze fluorescence intensity generated from a single image. B: Mean fluorescence intensity in anatomical subregions over time. Images were converted into 8-bit images and background was subtracted. Anatomical subregions of interest (ROI) were generated within Image-J to allow for analysis of pixels contained within the olfactory bulb (OB: black), septal nuclei (MSLS: red), thalamus (TH: green), granular insular cortex (Gl: violet), hippocampus (HP: turquoise), and deep mesencephalic nucleus (DMPE: orange) of all brains ( $n=3$ for $0,12,24,48,72$, and $96 \mathrm{~h}$ ). A ROI was defined using polarized light images of the sections corresponding to horizontal section from Paxinos and Watson atlas. Horizontal sections corresponding to $-5.32 \mathrm{~mm}$ ventral to bregma were analyzed. From each ROI, the mean and maximum fluorescence intensity was generated from a histogram depicting 256 possible grayscale units $(0=$ darkest, $256=$ brightest). The mean value of fluorescence indicates the overall fluorescence within a ROI.

kindling on a 24-h delivery schedule. Additionally, by modulating polymer characteristics and thus release rate, therapeutic levels may be more efficiently controlled in target tissue where long-term therapy is needed at higher concentrations. ${ }^{73}$ Similar to other, smaller neuropeptides,
TRH is a relatively stable compound that can be incorporated into polymeric devices in varying concentrations with minimal loss of bioactivity by proteolytic enzymes. ${ }^{58,60,74}$ The actual kinetics of TRH release from the nanoparticles has not been characterized in vivo. 

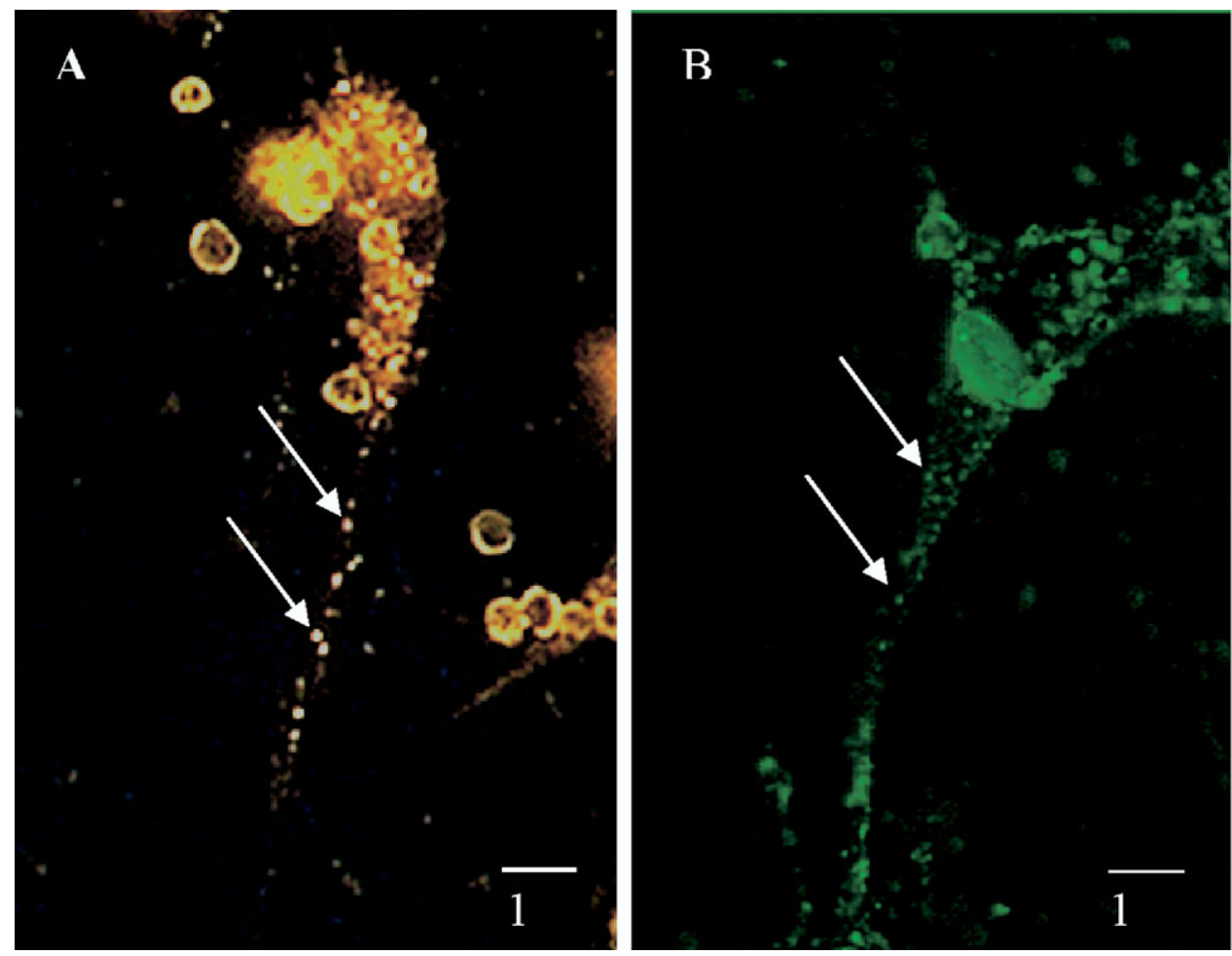

FIG. 8. Uptake of 100-nm Nile red NPs (A) and 20-nm polystyrene green fluorescent beads (B) into individual hippocampal neurons in vitro. Fetal hippocampal neurons were grown in serum-free medium containing neurobasal medium supplemented with $2 \%$ B-27 (Gibco, Grand Island, NY). This combination has been shown to reduce glia to less than $0.5 \%$. Medium 1 consisted of neurobasal medium, B-27 supplement, $200 \mathrm{mmol} / \mathrm{L}$ L-glutamine (Sigma-Aldrich, St. Louis, MO), basic fibroblast growth factor (BFGF) $(50 \mu \mathrm{mol} / \mathrm{L} / 12 \mathrm{~mL})$, and normocin $(2 \mu \mathrm{g} / \mathrm{mL})$, an antibiotic, as additional components, which further optimize neuronal growth and select against microbial contamination. After 14 days in culture, the differentiated neurons were removed from the incubator and the medium was carefully aspirated from the culture dishes to remove cellular debris. A $1 \mathrm{mg} / \mathrm{mL}$ stock solution of Nile red NPs (10 mg/mL PLA) was diluted with medium 1 to provide a final amount of $50 \mathrm{ng} / \mathrm{mL}$ medium $(500 \mathrm{ng} / \mathrm{mL}$ PLA). A $10 \mathrm{mg} / \mathrm{mL}$ stock solution of Blank-NPs was also diluted to provide a final amount of $500 \mathrm{ng} / \mathrm{mL}$ PLA and served as a nonfluorescent nanoparticle control. Neurons were incubated with either Nile red NPs $\left(100 \mathrm{~nm}\right.$ ) or $1 \times 10^{14} 20$-nm polystyrene fluorescent microspheres (FluoSpheres; Invitrogen-Molecular Probes, Eugene, OR) for $5 \mathrm{~h}$, then washed with PBS. Cells were fixed using 10\% formalin and viewed using a fluorescence microscope (Texas red/fluorescein isothiocyanate filter) at $60 \times$ magnification. A: A representative image of neuronal uptake of $100-n m$ Nile red NPs before or during release of Nile red NPs (arrows indicate individual NPs before or during release of Nile red within a process of a neuron). B: A representative Image of neuronal uptake of 20-nm yellow-green FluoSpheres (arrows indicate individual FluoSpheres within a process of a neuron). Blank NPs could not be detected (data not shown).

Future work in this area should provide insight into TRH site distribution, rates of degradation, and long-term receptor modulation.

\section{CONCLUSIONS}

Significant recent advances in the development of nontoxic biodegradable polymers in the form of microdisk and nanoparticle carriers suggest that such devices have a significant potential in delivering neuropeptides and perhaps other larger peptides to the brain. Intranasal delivery of neuropeptides directly to specific CNS targets using polymeric nanoparticles represents a new frontier in drug delivery. Advantages of this means of circumventing the BBB include ease of use, long-term compliance, uninterrupted delivery, ease of dosing, treatment schedules, and cost savings per dose. ${ }^{32,37-39,48,63,75-78}$ We have focused on intranasal delivery through olfactory neurons as a plausible means for targeting specific temporal lobe structures and disorders specifically associated with this CNS site. The neuroepithelium and neuroanatomy of the olfactory sensory system have important CNS synaptic terminations largely associated with limbic cortical and subcortical structures. Although the olfactory receptor neuron has direct contact with the external environment, it is known that several neuroprotective barriers exist that must first be permeated, without compromising barrier integrity, to successfully access the olfactory long tracts.

Questions related to intranasal neuropeptide uptake, transport, transneuronal transport, and terminal release have been considered. ${ }^{32,79}$ Even though intranasal drug delivery to the brain has been actively researched for some time with only marginal success, the development of newer sustained-release biodegradable nanoparticles (as in the work reported here) may render this approach more successful in enhancing neuropeptide bioavailability. 

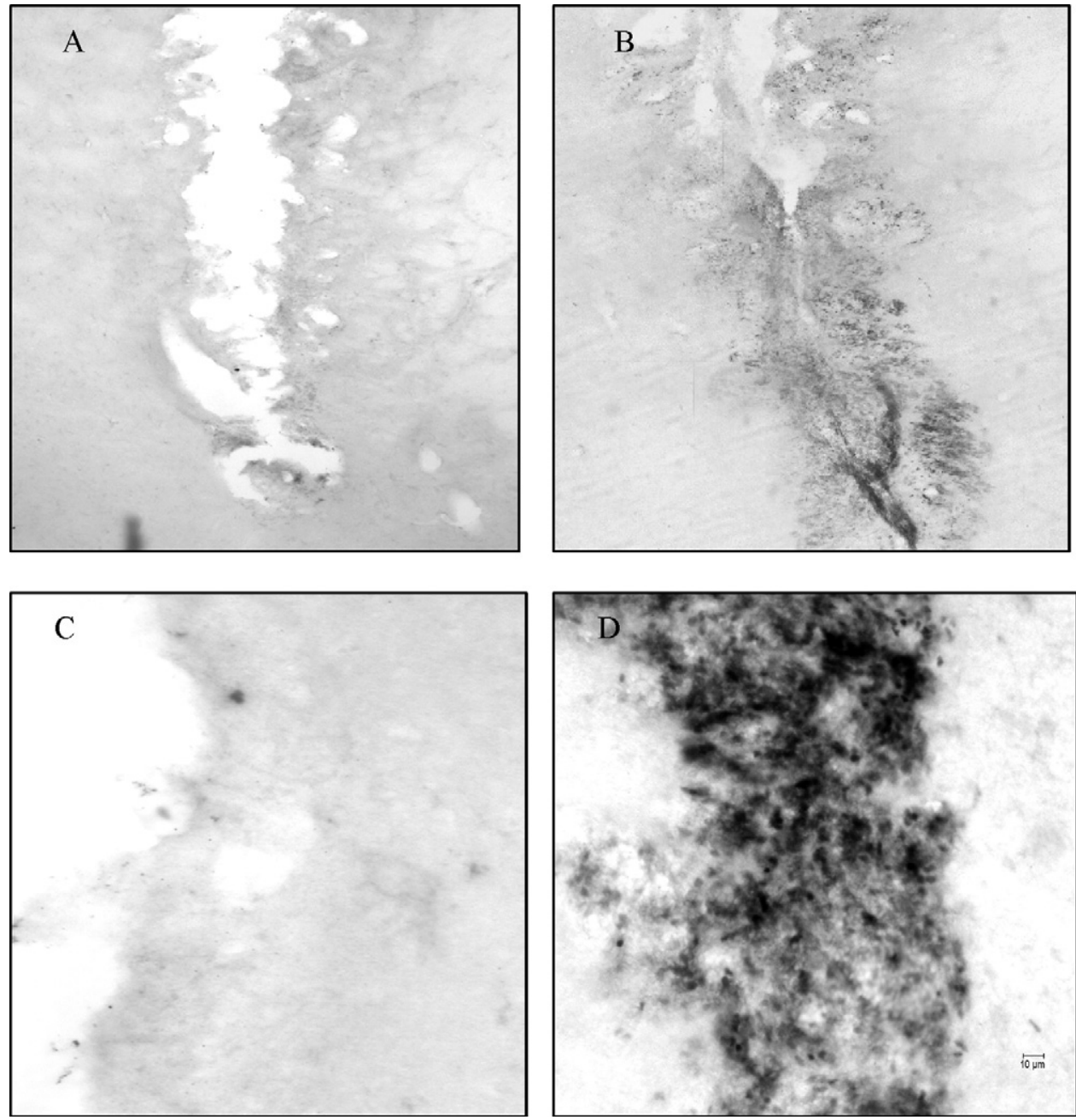

FIG. 9. Immunostaining of TRH nanoparticles $30 \mathrm{~min}$ after intra-amygdalar injection. A $10-\mu \mathrm{L}$ Hamilton syringe loaded with $10 \mu \mathrm{L}$ $(1 \mu \mathrm{g} / 1 \mu \mathrm{L}) \mathrm{TRH}-\mathrm{NPs}$ was inserted into the left basolateral amygdala (BLA) using stereotaxic coordinates from the atlas of Paxinos and Watson ${ }^{43}$ were injected slowly over $5 \mathrm{~min}$. The same procedure was conducted for Blank-NPs into the contralateral BLA. After 30 min, the animal was perfused and fixed and the brains sectioned using a sliding microtome (Leica SM 2000 R). Sections (30 $\mu \mathrm{m}) \mathrm{were}$ incubated in phosphate buffer containing a primary anti-rabbit TRH antibody (1:4000) produced in our lab, ${ }^{69}$ then washed and incubated with biotinylated goat anti-rabbit IgG secondary antibody (1:500) (BA-1000, Vector Labs, Burlingame, CA). After incubation with the rabbit IgG Vectastain ABC kit and Vector SG chromogen SK-4700 (Vector Laboratories Burlingame, CA), the sections were viewed under a light microscope at $5 \times$ and $40 \times$ magnification. Digital photos were acquired using Spot 4.0 imaging software (Diagnostic Instruments, Sterling Heights, MI). A: Image from a 30- $\mu \mathrm{m}$ section depicting injection site of Blank-NPs $(100 \mathrm{~nm})$ in the right BLA of a rat at $5 \times$. B: Image from the same section showing the injection site of TRH-NPs $(100 \mathrm{~nm})$ in the left BLA, at $5 \times$. C: Blank-NPs in the right BLA, at $40 \times$. D: TRH-NPs in the left BLA, at $40 \times$. Note the intense staining exclusively at the injection site of the TRH-NPs.

For now, we do not know the preferred route by which intranasally administered drugs and nanoparticles gain access to the CNS from the olfactory epithelium. At least three possibilities exist: 1) olfactory nerve uptake; 2) paracellular uptake; and 3) microvascular uptake. Understandably, this portal is the subject of extensive ongoing research. (For reviews, see Lockman et al. ${ }^{63}$ and Kubek et al. $^{79}$ ) An important consideration in the application of nose-to-brain nanoparticle delivery is that the particles must be delivered to the olfactory neuroepithelium, and not simply deposited into the respiratory epithelium. We feel that our nasal port system provides uniform and consistent access to the olfactory epithelium of the rat and could be modified for other animals as well. ${ }^{19} \mathrm{Hu}-$ man nasal applicators are commercially available that target the olfactory epithelium. These new devices can advance the development of intranasal nanoparticle drug delivery.

Overall, we have presented several lines of evidence that biodegradable nanoparticles provide a novel mechanism to overcome many obstacles for long-term continuous intranasal delivery of neuropeptides to the brain. As reviewed herein, TRH delivered to these sites in sufficient concentrations is known to attenuate seizures. ${ }^{16,17,19,56}$ Therefore, it seems reasonable to conclude that certain neuropeptides and perhaps other drugs can be delivered safely and repeatedly using intranasal nanoparticles as sustainedrelease carriers to enhance bioavailability to clinically rel- 
evant CNS targets. In this fashion, TRH-NPs may provide an alternative treatment that could significantly impede or possibly prevent epileptogenesis where more conventional therapies have not been successful. Clearly, much more pharmacokinetic and pharmacotherapeutic research is necessary to optimize this intranasal neuropeptide carrier system. Because both TRH and its carrier polyanhydride have been used clinically, the immediate goal is to design a TRH-NP that could serve as the prototype for the intranasal delivery of other anticonvulsant neuropeptides such as neuropeptide $\mathrm{Y}$, galanin, somatostatin, and adrenocorticotropic hormone.

Acknowledgments: This work was sponsored in part by grants from Citizens United for Research in Epilepsy (CURE) (M.J.K.), Indiana University-Purdue University Indianapolis IUPUI Research Venture Award (M.J.K.) and the Bi-national Science Foundation (Israel and United States) (M.J.K., A.J.D.). The authors thank Dr. William Truitt, Mr. Dan Kubek, Ms. Amanda Weinert, Ms. Amy Dietrich, and Mr. Yanir Aldouby for their expert technical assistance; Ms. Cynthia Cally, Division of Biostatistics, for statistical advice; and Dr. Debomoy Lahiri, Departments of Psychiatry and Medical \& Molecular Genetics, for expert assistance in the preparation of this manuscript.

\section{REFERENCES}

1. Kubek MJ, Lorincz MA, Wilber JF. The identification of thyrotropin releasing hormone (TRH) in hypothalamic and extrahypothalamic loci of the human nervous system. Brain Res 1977;126: 196-200.

2. Kubek MJ. Thyrotropin-releasing hormone: localization of specific hypothalamic and extrahypothalamic sites of CNS modulation. In: Frederickson RCA, Hendrie H, Hingtgen JN, Aprison MH, editors. Neuroregulation of autonomic, endocrine and, immune systems. Boston: Martinus-Nijhoff, 1986:265-301.

3. Manaker S, Engber TM, Knight PB, Winokur A. Intraventricular 5,7-dihydroxytryptamine increases thyrotropin-releasing hormone content in regions of rat brain. J Neurochem 1985;45:1315-1318.

4. Nillni EA, Sevarino KA. The biology of pro-thyrotropin-releasing hormone-derived peptides. Endocr Rev 1999;20:599-648.

5. Heuer H, Schäfer MK, O'Donnell D, Walker P, Bauer K. Expression of thyrotropin-releasing hormone receptor 2 (TRH-R2) in the central nervous system of rats. J Comp Neurol 2000;428:319-336.

6. Gary KA, Sevarino KA, Yarbrough GG, Prange AJ Jr, Winokur A. The thyrotropin-releasing hormone (TRH) hypothesis of homeostatic regulation: implications for TRH-based therapeutics. J Pharmacol Exp Ther 2003;305:410-416.

7. Manaker S, Rainbow TC, Winokur A. Thyrotropin-releasing hormone (TRH) receptors: localization in rat and human central nervous system. In: Boast C, Snowhill E, Altar CA, editors. Quantitative receptor autoradiography. New York: Alan R. Liss, 1986: $103-135$.

8. Kubek MJ, Sattin A. Effect of electroconvulsive shock on the content of thyrotropin-releasing hormone in rat brain. Life Sci 1984;34:1149-1152.

9. Kubek MJ, Meyerhoff JL, Hill TG, Norton JA, Sattin A. Effects of subconvulsive and repeated electroconvulsive shock on thyrotropin-releasing hormone in rat brain. Life Sci 1985;36:315-320.

10. Rosen JB, Abramowitz J, Post RM. Colocalization of TRH mRNA and Fos-like immunoreactivity in limbic structures following amygdala kindling. Mol Cell Neurosci 1993;4:335-342.

11. Knoblach SM, Kubek MJ. Thyrotropin-releasing hormone release is enhanced in hippocampal slices after electroconvulsive shock. J Neurochem 1994;62:119-125.

12. Knoblach SM, Kubek MJ. Increases in thyrotropin-releasing hormone messenger RNA expression induced by a model of human temporal lobe epilepsy: effect of partial and complete kindling. Neuroscience 1997;76:85-95.

13. Gu J, Lynch BA, Anderson D, et al. The antiepileptic drug levetiracetam selectively modifies kindling-induced alterations in gene expression in the temporal lobe of rats. Eur J Neurosci 2004;19: 334-345.

14. Wilson DN, Chung H, Elliott RC, Bremer E, George D, Koh S. Microarray analysis of postictal transcriptional regulation of neuropeptides. J Mol Neurosci 2005;25:285-298.

15. Kubek MJ, Low WC, Sattin A, Morzorati SL, Meyerhoff JL, Larsen SH. Role of TRH in seizure modulation. Ann N Y Acad Sci 1989;553:286-303.

16. Kubek MJ, Liang D, Byrd KE, Domb AJ. Prolonged seizure suppression by a single implantable polymeric-TRH microdisk preparation. Brain Res 1998;809:189-197.

17. Wan RQ, Noguera EC, Weiss SR. Anticonvulsant effects of intrahippocampal injection of TRH in amygdala kindled rats. Neuroreport 1998;9:677-682.

18. Jaworska-Feil L, Kajta M, Budziszewska B, Leśkiewicz M, Lasoń W. Protective effects of TRH and its stable analogue, RGH-2202, on kainate-induced seizures and neurotoxicity in rodents. Epilepsy Res 2001;43:67-73.

19. Veronesi MC, Kubek DJ, Kubek MJ. Intranasal delivery of a thyrotropin-releasing hormone analog attenuates seizures in the amygdala-kindled rat. Epilepsia 2007;48:2280-2286.

20. Rajput SK, Krishnamoorthy S, Pawar C, et al. Antiepileptic potential and behavioral profile of L-pGlu-(2-propyl)-L-His-L-ProNH $\mathrm{N}_{2}$, a newer thyrotropin-releasing hormone analog. Epilepsy Behav 2009;14:48-53.

21. Kubek MJ, Garg BP. Thyrotropin-releasing hormone (TRH) in the treatment of intractable epilepsy. Pediatr Neurol 2002;26:9-17.

22. Takeuchi Y. Thyrotropin-releasing hormone (protirelin): role in the treatment of epilepsy. CNS Drugs 1996;6:341-350.

23. Takeuchi Y, Takano T, Abe J, Takikita S, Ohno M. Thyrotropinreleasing hormone: role in the treatment of West syndrome and related epileptic encephalopathies. Brain Dev 2001;23:662-667.

24. Matsumoto A, Kumagai T, Takeuchi T, Miyazaki S, Watanabe K. Factors influencing effectiveness of thyrotropin-releasing hormone therapy for severe epilepsy in childhood: significance of serum prolactin levels. Epilepsia 1989;30:45-49.

25. Nie Y, Schoepp DD, Klaunig JE, Yard M, Lahiri DK, Kubek MJ. Thyrotropin-releasing hormone (protirelin) inhibits potassiumstimulated glutamate and aspartate release from hippocampal slices in vitro. Brain Res 2005;1054:45-54.

26. Veronesi MC, Yard M, Jackson J, Lahiri DK, Kubek MJ. An analog of thyrotropin-releasing hormone (TRH) is neuroprotective against glutamate-induced toxicity in fetal rat hippocampal neurons in vitro. Brain Res 2007;1128:79-85.

27. Schomburg L, Turwitt S, Prescher G, Lohmann D, Horsthemke B, Bauer K. Human TRH-degrading ectoenzyme cDNA cloning, functional expression, genomic structure and chromosomal assignment. Eur J Biochem 1999;265:415-422.

28. Heuer H, Schäfer MKH, Bauer K. The thyrotropin-releasing hormone-degrading ectoenzyme: the third element of the thyrotropinreleasing hormone-signaling system. Thyroid 1998;8:915-920.

29. Born J, Lange T, Kern W, McGregor GP, Bickel U, Fehm HL. Sniffing neuropeptides: a transnasal approach to the human brain. Nat Neurosci 2002;5:514-516.

30. Smolnik R, Molle M, Fehm HL, Born J. Brain potentials and attention after acute and subchronic intranasal administration of ACTH 4-10 and desacetyl- $\alpha$-MSH in humans. Neuroendocrinology 1999;70:63-72.

31. Illum L. Nasal drug delivery: possibilities, problems and solutions. J Control Release 2003;87:187-198.

32. Kubek MJ, Yard M, Lahiri DK, Domb AJ. Characterization of novel intranasal sustained-release nanoparticles for delivery of neuropeptides to the brain. In: Domb AJ, Tabata Y, Ravi Kumar MNV, Farber S, editors. Nanoparticles for pharmaceutical applications. New York: American Scientific Publishers, 2007:73-84.

33. Shipley MT. Transport of molecules from nose to brain: transneuronal anterograde and retrograde labeling in the rat olfactory system by wheat germ agglutinin-horseradish peroxidase applied to the nasal epithelium. Brain Res Bull 1985;15:129-142. 
34. Broadwell RD, Balin BJ, Salcman M. Transcytotic pathway for blood-borne protein through the blood-brain barrier. Proc Natl Acad Sci U S A 1988;85:632-636.

35. Balin BJ, Broadwell RD. Transcytosis of protein through the mammalian cerebral epithelium and endothelium: I. Choroid plexus and the blood-cerebrospinal fluid barrier. J Neurocytol 1988;17:809-826.

36. Morrison EE, Moran DT. Anatomy and ultrastructure of the human olfactory neuroepithelium. In: Doty RL, editor. Handbook of olfaction and gustation. New York: Marcel Dekker, 1995:75-101.

37. Mathison S, Nagilla R, Kompella UB. Nasal route for direct delivery of solutes to the central nervous system: fact or fiction? J Drug Target 1998;5:415-441.

38. Thorne RG, Emory CR, Ala TA, Frey WH 2nd. Quantitative analysis of the olfactory pathway for drug delivery to the brain. Brain Res 1995;692:278-282.

39. Illum L. Transport of drugs from the nasal cavity to the central nervous system. Eur J Pharm Sci 2000;11:1-18.

40. Löscher W. Animal models of epilepsy for the development of antiepileptogenic and disease-modifying drugs: a comparison of the pharmacology of kindling and post-status epilepticus models of temporal lobe epilepsy. Epilepsy Res 2002;50:105-123.

41. Goddard GV, McIntyre DC, Leech CK. A permanent change in brain function resulting from daily electrical stimulation. Exp Neurol 1969;25:295-330.

42. Racine RJ. Modification of seizure activity by electrical stimulation: I. after-discharge threshold. Electroencephalogr Clin Neurophysiol 1972;32:269-279.

43. Paxinos G, Watson C. The rat brain in stereotaxic coordinates. 2nd ed. New York: Academic Press, 1986.

44. Brem H, Piantadosi S, Burger PC, et al.; the Polymer-Brain Tumor Treatment Group. Placebo-controlled trial of safety and efficacy of intraoperative controlled delivery by biodegradable polymers of chemotherapy for recurrent gliomas. Lancet 1995;345:1008-1012.

45. O'Dowd BF, Lee DK, Huang W, et al. TRH-R2 exhibits similar binding and acute signaling but distinct regulation and anatomic distribution compared with TRH-R1. Mol Endocrinol 2000;14:183-193.

46. Calzá L, Giardino L, Ceccatelli S, Zanni M, Elde R, Hökfelt T. Distribution of thyrotropin-releasing hormone receptor messenger RNA in the rat brain: an in situ hybridization study. Neuroscience 1992;51:891-909.

47. Przewłocka B, Labuz D, Mika J, et al. Protective effects of TRH and its analogues in chemical and genetic models of seizures. Pol J Pharmacol 1997;49:373-378.

48. Wermeling DP, Miller JL, Rudy AC. Systemic intranasal drug delivery: concepts and applications. Drug Deliv Technol 2002;2:22-30.

49. Wermeling DP, Record KA, Archer SM, Rudy AC. A pharmacokinetic and pharmacodynamic study, in healthy volunteers, of a rapidly absorbed intranasal midazolam formulation. Epilepsy Res 2009;83:124-132.

50. Hanson LR, Frey WH. Intranasal delivery bypasses the blood-brain barrier to target therapeutic agents to the central nervous system and treat neurodegenerative disease. BMC Neurosci 2008;9 Suppl 3:S5.

51. Chen XQ, Fawcett JR, Rahman YE, Ala TA, Frey WH 2nd. Delivery of nerve growth factor to the brain via the olfactory pathway. J Alzheimers Disease 1998;1:35-44.

52. Frey WH 2nd, Liu J, Chen XQ, et al. Delivery of 125I-NGF to the brain via the olfactory route. Drug Delivery 1997;4:87-92.

53. Thorne RG, Hanson LR, Ross TM, Tung D, Frey WH 2nd. Delivery of interferon- $\beta$ to the monkey nervous system following intranasal administration. Neuroscience 2008;152:785-797.

54. Alcalay RN, Giladi E, Pick CG, Gozes I. Intranasal administration of NAP, a neuroprotective peptide, decreases anxiety-like behavior in aging mice in the elevated plus maze. Neurosci Lett 2004;361: $128-131$

55. Matsuoka Y, Gray AJ, Hirata-Fukae C, et al. Intranasal NAP administration reduces accumulation of amyloid peptide and tau hyperphosphorylation in a transgenic mouse model of Alzheimer's disease at early pathological stage. J Mol Neurosci 2007;31:165-170.

56. Chepurnov SA, Chepurnova NE, Abbasova KR, Goncharov OB. Neuropeptide thyroliberin--an endogenous anticonvulsant in the brain [In Russian]. Usp Fiziol Nauk 2002;33:29-39.
57. Schmutz M, Klebs K. Kindling and antiepileptic drugs. In: Bolwig TG, Trimble MR, editors. The clinical relevance of kindling. New York: John Wiley \& Sons, 1989:55-68.

58. Domb AJ. Implantable biodegradable polymers for site-specific drug delivery. In: Domb AJ, editor. Polymeric site-specific pharmacotherapy. Chichester, England: John Wiley \& Sons, 1994:1-26.

59. Domb A, Maniar M, Bogdansky S, Chasin M. Drug delivery to the brain using polymers. Crit Rev Ther Drug Carrier Syst 1991;8:1-17.

60. Domb AJ, Kubek MJ. Synthesis of Poly(carboxyphenoxypropanesebacic anhydride) for the delivery of drugs to the brain. In: Kobiler D, Lustig S, Shapira S, editors. Blood-brain barrier: drug delivery and brain pathology. New York: Kluwer Academic/Plenum Publishers, 2001:351-362.

61. Hashimoto T, Wada T, Fukuda N, Nagaoka A. Effect of thyrotropin-releasing hormone on pentobarbitone-induced sleep in rats: continuous treatment with a sustained release injectable formulation. J Pharm Pharmacol 1993;45:94-97.

62. Ogata A, Nagashima K, Yasui K, Matsuura T, Tashiro K. Sustained release dosage of thyrotropin-releasing hormone improves experimental Japanese encephalitis virus-induced parkinsonism in rats. J Neurol Sci 1998;159:135-139.

63. Lockman PR, Mumper RJ, Khan MA, Allen DD. Nanoparticle technology for drug delivery across the blood-brain barrier. Drug Dev Ind Pharm 2002;28:1-13.

64. Gao X, Tao W, Lu W, et al. Lectin-conjugated PEG-PLA nanoparticles: preparation and brain delivery after intranasal administration. Biomaterials 2006;27:3482-3490.

65. Veronesi MC, Weinert AD, Aldouby Y, Domb AJ, Kubek MJ. Intranasal delivery of thyrotropin-releasing hormone $\mathrm{D}, \mathrm{L}$ polylactide nanoparticles (TRH-NPs) suppresses kindling development in the rat. Submitted.

66. Kubek MJ, Domb AJ, Kubek DJ, Veronesi MC. Thyrotropinreleasing hormone nanoparticles (TRH-NPs): effects on glutamate toxicity, in vitro, and kindled seizures, in vivo. Soc Neurosci Abstr 2008.451.14 (abstract)

67. Bishara A, Domb AJ. PLA stereocomplexes for controlled release of somatostatin analogue. J Control Release 2005;107:474-483.

68. Veronesi MC, Kubek DJ, Domb AJ, Kubek MJ. Uptake, subregional distribution and time course of intranasally delivered Nile red sustained-release nanoparticles in the rat brain. Soc Neurosci Abstr 2007.166.19 (abstract).

69. Kubek MJ, Hill TG. Methods of thyrotropin-releasing hormone measurement. In: Hingtgen JN, Hellhammer D, Huppmann G, editors. Advanced methods in psychobiology. Toronto: Hogrefe, 1987:261-279.

70. Kissel T, Werner U. Nasal delivery of peptides: an in vitro cell culture model for the investigation of transport and metabolism in human nasal epithelium. J Control Rel 1998;53:195-203.

71. Vinogradov SV, Bronich TK, Kabanov AV. Nanosized cationic hydrogels for drug delivery: preparation, properties and interactions with cells. Adv Drug Deliv Rev 2002;54:135-147.

72. Vila A, Sánchez A, Evora C, Soriano I, McCallion O, Alonso MJ. PLA-PEG particles as nasal protein carriers: the influence of the particle size. Int J Pharm 2005;292:43-52.

73. Panyam J, Labhasetwar V. Biodegradable nanoparticles for drug and gene delivery to cells and tissue. Adv Drug Deliv Rev 2003; 55:329-347.

74. Gombotz WR, Pettit DK. Biodegradable polymers for protein and peptide drug delivery. Bioconjug Chem 1995;6:332-351.

75. Baker H. Transport phenomena within the olfactory system. In: Doty RL, editor. Handbook of olfaction and gustation. New York: Marcel Dekker, 1995:173-190.

76. Gozes I, Brenneman DE, Geppetti P, et al. Neuropeptides: brain messengers of many faces. Trends Neurosci 2001;24:687-690.

77. Illum L. Is nose-to-brain transport of drugs in man a reality? J Pharmacy Pharmacology 2004;56:3-17.

78. Agarwal V, Mishra B. Recent trends in drug delivery systems: intranasal drug delivery. Indian J Exp Biol 1999;37:6-16.

79. Kubek MJ, Ringel I, Domb AJ. Issues related to intranasal delivery of neuropeptides to temporal lobe targets. In: Kobiler D, Lustig S, Shapira S, editors. Blood-brain barrier: drug delivery and brain pathology. New York: Kluwer Academic/Plenum Publishers, 2001:323-350. 